\title{
ON SOME FIXED POINT THEOREMS
}

\author{
D. ROUX and S.P. SINGH \\ Dipartimento di Matematica \\ Universite di Milano \\ Via C. Saldini 50 \\ 20133 Milano, Italy \\ Department of Mathematics \\ Memorial University \\ st. John's, NF, Canada, A1C 5S7
}

(Received Apri1 1, 1987 and in revised form October 26, 1987)

ABSTRACT. In this paper we prove a fixed point theorem for inward mappings using a well-known result of $\mathrm{Ky}$ Fan type in Hilbert space setting.

KEY WORDS AND PHRASES. Semicontractive map, fixed points, nonexpansive maps. 1980 MATHEMATICS SUBJECT CLASSIFICATIONS: Primary 47H10, Secondary $54 \mathrm{H} 25$.

The following well known theorem of Ky Fan has been of great importance in nonlinear analysis, minimax theory and approximation theory [1].

Let $\mathrm{C}$ be a nonempty compact, convex subset of a normed linear space $\mathrm{X}$ and let $\mathrm{f}: \mathrm{C} \rightarrow \mathrm{X}$ be a continuous mapping. Then there exists a $y \in C$ such that

$$
\left\|_{y}-f_{y}\right\|=d\left(f_{y}, C\right) \text {, }
$$

where $d(a, B)=\inf \{\|a-b\| / b \in B\}$.

If $f_{y} \in C$, then $f$ has a fixed point.

There have appeared several extensions of Ky Fan theorem. Lin (2) proved an interesting result for densifying mappings. Reich [3] relaxed compactness and proved the result for approximately compact, convex sets. Other results are due to sehgal [4], Sehgal and Singh [5], Kapoor [6] and Singh and watson [7].

In the present paper we prove a fixed point theorem for inward mappings using a result of Ky Fan type theorem for Hilbert space. For definitions and notations we refer to Browder [8]. We will use his results for our theorem. 
Let $\mathrm{C}$ be a closed, bounded, convex subset of $\mathrm{H}$, a Hilbert space. A function $\mathrm{f}: \mathrm{C} \rightarrow \mathrm{H}$ is called semicontractive if there exists a mapping $\mathrm{T}$ of $\mathrm{H} \times \mathrm{H} \rightarrow \mathrm{C}$ such that

i) $f(x)=T(x, x)$ for $x \in C$, while

ii) for fixed $x \in H, T(\cdot, x)$ is nonexpansive,

iii) for fixed $x \in H, T(x, \cdot)$ is compact.

Recall that $f: H \rightarrow H$ is nonexpansive if ||$f x-f y|| \leq|| x-y||$

for all $x, y \in H$.

The following is a special case of a well-known theorem of

Browder [8]. (We state it in Hilbert space).

Let $C$ be a closed, bounded, convex subset of a Hilbert space $H$ and let $f: C \rightarrow C$ be a semicontractive mapping. Then $f$ has a fixed point.

The following more general result holds.

THEOREM 1. Let $C$ be a nonempty, closed, convex subset of a Hilbert space $H$ and let $\mathrm{f}: \mathrm{C} \rightarrow \mathrm{H}$ be semicontractive mapping such that $f(C)$ is bounded. Then there exists a $y \in C$ such that

$$
\left\|_{Y}-f_{Y}\right\|=d\left(f_{Y}, C\right) \text {. }
$$

PROOF: Let $\mathrm{P}: \mathrm{H} \rightarrow \mathrm{C}$ be the proximity map. Then $\mathrm{P}$ is a nonexpansive map, i.e.

$$
\left\|P_{X}-P y\right\| \leq\|x-y\| \text { for all } x, y \in H \text {. (see [9]). }
$$

Also,

Pof : $\mathrm{C} \rightarrow \mathrm{C}$.

Let $B=\bar{C}_{0}(P f(C))$, convex closure of $(P f(C))$.

Then Pf: $B \rightarrow B$ is a semicontractive mapping and has a fixed point say $\operatorname{Pf}_{Y}=Y$.

Therefore $\left\|y-f_{y}\right\|=\left\|P f_{y}-f y\right\|$

$$
=d\left(f_{y}, C\right) \text {. }
$$

COROLLARY 1 .

Let $C$ be a closed, bounded and convex subset of $H$ and let $\mathrm{f}: \mathrm{C} \rightarrow \mathrm{H}$ be a semicontractive. Then there exists a $y \in C$ such that

$$
\|y-f y\|=d(f y, c) \text {. }
$$

Let us now recall the "inwardness condition". Let $K$ be a closed subset of a Banach space $X$. We say that $f: K \rightarrow X$ is an inward mapping if for every $x \in K$ 


$$
f x \in I_{k}(x)=\{z: z=x+\alpha(y-x) \in K, \alpha \geq 0\}
$$

This condition introduced by Halpern [10] and [11] is weaker than

$x \in \delta K \Rightarrow f(x) \in K$ and is widely used in order to obtain fixed point

results for mappings $f: K \rightarrow X$. See e.g. Assad and Kirk [12], Carist 1

[13], Caristi and Kirk [14], Downing and Kirk [15], S. Reich [3], Downing and Ray [16] and S. Massa [17], [18]. ( $\delta \mathrm{K}$ stands for boundary of $K)$.

S. Massa [18] pointed out that if $K$ is a convex set $C(K=C)$ then the inwardness condition is equivalent to

$$
x \in C \Rightarrow(x, f x] \cap C \neq \phi
$$

where $(x, y]=[(1-\alpha) x+\alpha y, 0<\alpha \leq 1]$.

THEOREM 2. Let $\mathrm{C}$ be a closed, convex subset of a Hilbert space $\mathrm{H}$ and $\mathrm{f}: \mathrm{C} \rightarrow \mathrm{H}$ be a semicontractive inward mapping with bounded range. Then $f$ has a fixed point.

PROOF. Let $y \in C$ be such that

$$
\left\|y-f_{y}\right\|=d\left(f_{y}, C\right) . \quad \text { (By Theorem 1). }
$$

Suppose $y \neq f_{Y}$. Then $f_{y} \notin C$ and there exists a $z \in\left(y, f_{y}\right) \cap C$ We have

$$
\left\|y-f_{y}\right\|=\left\|_{Y}-z\right\|+\left\|z-f_{Y}\right\| \text {. }
$$

Then $d\left(f_{y}, C\right) \geq\left\|_{y}-z\right\|+d\left(f_{y}, C\right)$

absurd, because $y \neq z$.

COROLLARY 2 .

Let $C$ be a closed, convex subset of $H$ and let $f: C \rightarrow H$ be semicontractive with bounded range. If $f(\delta C) \subseteq C$, then $f$ has a fixed point.

COROLLARY 3 .

Let $B_{r}$ be a closed ball of radius $r$ and center 0 in $a$ Hilbert space $\mathrm{H}$. Let $\mathrm{f}: \mathrm{B}_{\mathrm{r}} \rightarrow \mathrm{H}$ be a semicontractve mapping satisfying the condition: if $f x=\alpha x$ for $x \in \delta B_{x}$ then $\alpha \leq 1$. Then $f$ has a fixed point.

ACKNOWLEDGEMENTS: The authors wish to thank Professor V. M. Sehgal for his help during the preparation of this paper. This work was partially supported by NSERC grant A5154 while the second author was a CNR Visiting Professor in the University of Milano, Italy. 


\section{References}

1. FAN, Ky. Extensions of two fixed point theorems of F. E. Browder, Math. Z. 112(1969), 234-240.

2. LIN, T. C. A note on a theorem of Ky Fan, Canadian Math. Bulletin $22(1979), 415-515$.

3. REICH, S. Approximate Selections, Best Approximations, Fixed Points and Invariant sets, J. Math. Anal. App1. 62 (1978), 104-113.

4. SEHGAL, V. M. A Simple Proof of a Theorem of Ky Fan, Proc. Amer. Math. Soc. 63(1977), 368-369.

5. SEHGAL, V. M. and SINGH, S. P. A Variant of a Fixed Point Theorem of Ky Fan, Indian J. of Math. 25 (1983), 171-174.

6. KAPOOR, O. P. TwO applications of an Intersection Lemma, J. Math. Anal. \& Appl. 41 (1973), 226-233.

7. SINGH, S. P. and WATSON, B. Proximity maps and Fixed Points, J. Approx. Theory, 39(1983), 72-76.

8. BROWDER, F. E. Fixed Point Theorems for nonlinear semicontractive mappings in Banach spaces, Arch. Rat. Mech. \& Anal. 21 (1966), 259-269.

9. CHENEY, E. W. and Goldstein, A. A. Proximity maps for convex sets, Proc. Amer. Math. Soc. 10, (1959), 448-450.

10. HALPERN, B. Fixed Point Theorems for outward maps, Doctoral thesis, U.C.L.A., (1965).

11. HALPERN, B. and BERGMAN, G. A Fixed point theorem for inward and outward maps. Trans. Amer. Math. Soc. 130 (1968), 353-358.

12. ASSAD, N. A. and KIRK, W. A. Fixed Point Theorems for set-valued mappings of contractive type, Pacif. J. Math. 43(1972), 553-562.

13. CARISTI, J. Fixed point theorems for mappings satisfying inward conditions, Trans. Amer. Math. Soc. 215(1976), 241-251.

14. CARISTI, J. and KIRK, W. A. Geometric Fixed Point Theory and Inwardness conditions, The Geometry of Metric Linear spaces, Proc., Ed. L. M. Kelly, Lecture Notes in Math. Springer-Verlag.

15. DOWNING, D. J. and KIRK, W. A. Fixed Pont Theorems for set-valued mappings in metric and Banach spaces, Math. Japonicae 22 (1977), 99-112.

16. DOWNING, D. J. and RAY, W. O. Some Results in set-valued mappings, Nonlinear Analysis, $\underline{5}(1981), 1367-1377$.

17. MASSA, S. Nonexpansive mappings with noncompact values, Atti. Accad. Sci. Torino, Sci. Fis. Mat. Natur, 117 (1983), 35-41.

18. MASSA, S. Some Remarks on Opial Spaces, Boll. Un. Mat. Ital., (6), 2-A(1983), 65-70. 


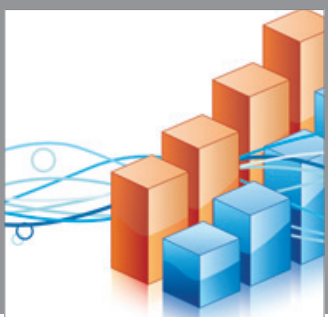

Advances in

Operations Research

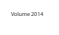

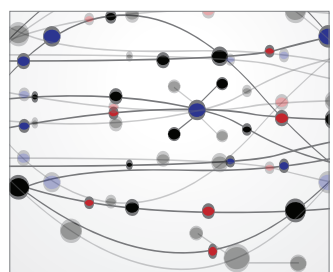

\section{The Scientific} World Journal
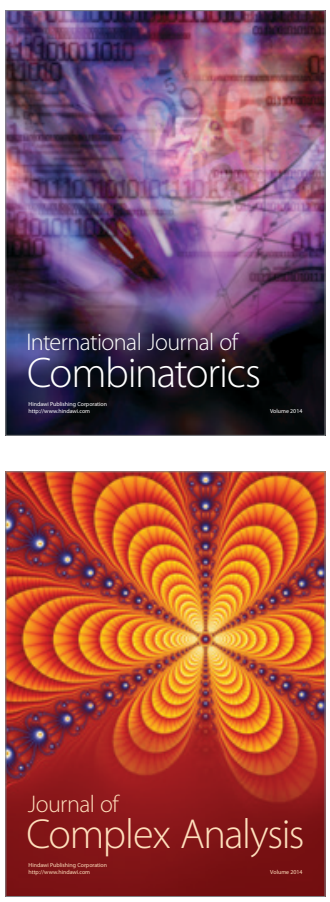

International Journal of

Mathematics and

Mathematical

Sciences
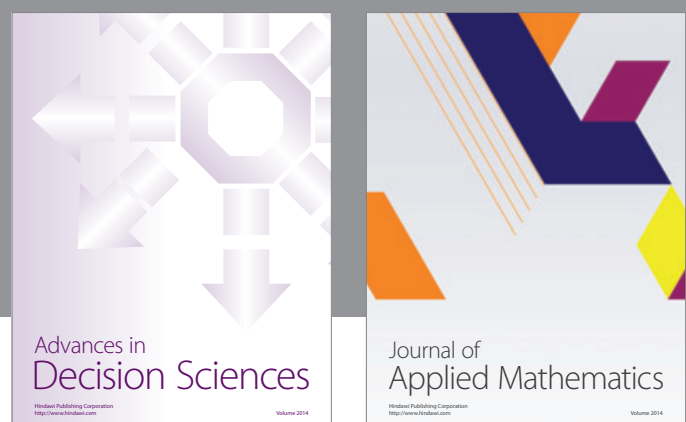

Journal of

Applied Mathematics
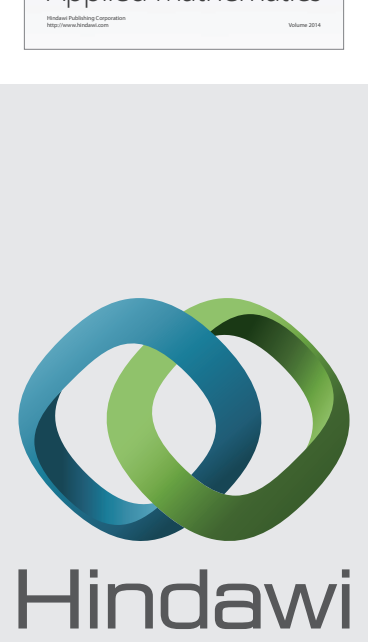

Submit your manuscripts at http://www.hindawi.com
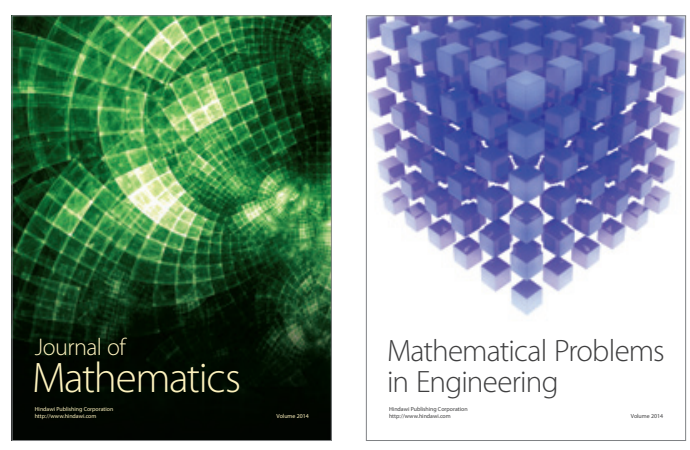

Mathematical Problems in Engineering
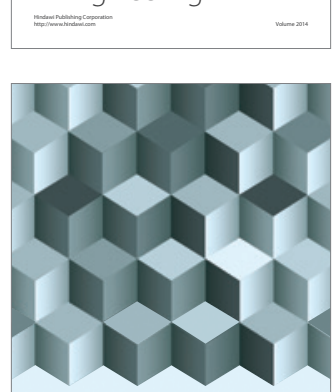

Journal of

Function Spaces
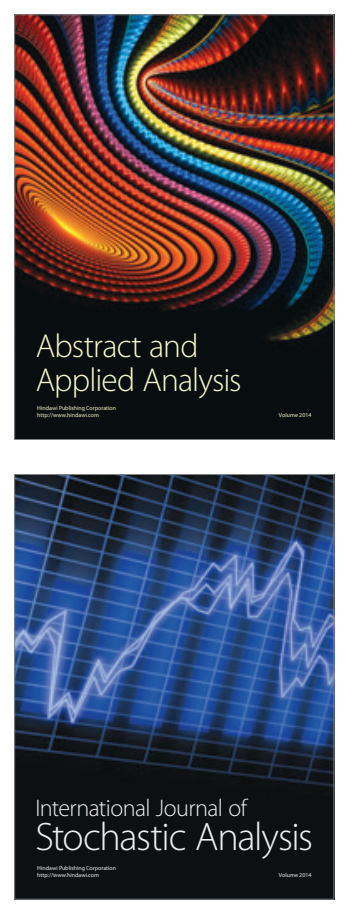

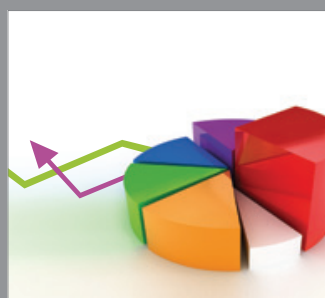

ournal of

Probability and Statistics

Promensencen
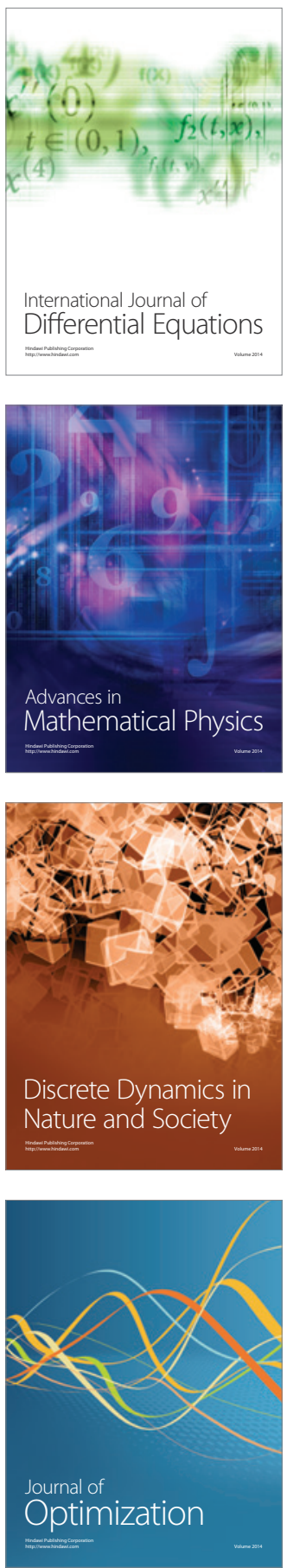